\title{
ENVIRONMENTAL BARRIERS TO REINTEGRATION EXPERIENCED BY STROKE CLIENTS POST DISCHARGE FROM A REHABILITATION CENTRE IN MALAWI
}

\begin{abstract}
Although stroke clients undergo rehabilitation to minimise the impact of stroke on their functioning, they still experience challenges with reintegration. The aim of this paper is to report on the environmental barriers to reintegration experienced by patients with stroke post discharge from a rehabilitation centre in Malawi. A qualitative research approach was adopted to explore the perceived barriers to reintegration experienced by the participants. In-depth interviews were utilised to capture data from perspectives of stroke clients. The data was analysed using content analysis. The findings of this study show key environmental barriers challenging community reintegration among the stroke clients, which included changes in relationship with relatives and friends as well as employers. The physical environmental barriers experienced included poor terrain, long distance to places of interest,and inaccessible structures. The findings of this study highlight the need to reduce the barriers to reintegration. Service providers could use the findings to consider addressing the potential negative contextual factors to reintegration when managing stroke clients.
\end{abstract}

KEY WORDS: STROKE CLIENTS, ENVIRONMENTAL BARRIERS, REINTEGRATION, REHABILITATION, MALAWI

\section{INTRODUCTION}

Stroke is a medical emergency that can cause permanent neurological complications and sometimes death (WHO 2005). With the rising incidence and morbidity rate of stroke, particularly in the poorer countries, which include Malawi (Heeley et al 2011), failure to perform activities and participate in socioeconomic activities by the clients after stroke (Blonderaet al 2007 and Cottet al 2007) are a major developmental challenge to affected individuals, their families and communities.

Barriers to the reintegration of stroke clients into the community are seen at individual and environmental levels. At individual level, Kochi et al

\section{Corresponding Author:}

Prof A Rhoda

University of the Western Cape

Private Bag X17

Bellville

7535

Email:arhoda@uwc.ac.za
(2005) reported that stroke clients have problems returning to work because of fatigue, depression and cognitive problems related to thought processing. The inability to return to work or other economic activities affect stroke clients' ability to resume their roles in the family and community, because their ability to generate income is affected. Socially, stroke clients may not manage to go out for recreation (Mayo et al 2002) owing to their impairments. It has also been found that demographic features also affect the level of reintegration in the community. Chau et al (2009) report that female stroke participants have lower self-esteem than male participants, and are therefore less likely to take part in post stroke social and leisure activities. The presence of other conditions in a stroke client may also limit the person's ability to remain active and participative in the community (WHO 2001). For instance, Chau et al (2009) associate old age with limited outdoor activities.

Environmentally,stroke clients, just like other people living with disability, experience architectural barriers. They have difficulty accessing buildings and transport. This leads to the clients remaining excluded, or making them dependent on others (The Dakar Framework of Action 2000). Buildings with steps, inaccessible public transport, and inaccessible education and health facilities have been noted as limiting physically challenged persons' participation,mostly in developing countries such as Malawi (Yeo and Moor 2003 and Loeb and Eide 2004). In addition,Venter et al (2002) highlight geographical features such as sandy roads in Maputo and steep slopes in Blantyre as limiting the mobility of persons with disabilities, including those in wheelchairs.

Stroke clients also experience attitudinal barriers. Venter et al (2002) have found that the attitudes shown in the driving behaviour of drivers of public transport, as well as overcrowding in the streets, constitute major barriers to using public transport by people with disabilities. In a qualitative study by Garcia et al (2000) the participating service 
providers pointed out that some community members who come in contact with stroke clients may have attitudinal problems. This supports the observation that in many societies, attitudes held by people towards a disabled member and their families constitute barriers to participation by persons with disabilities (Yeo and Moor 2003).

Most African countries, including Malawi, are predominantly rural (Loeb and Eide 2004), where people are mostly small-scale farmers with different conditions to those of urbanised or industrialised countries. Therefore most of the research findings about the type and magnitude of challenges of people living with stroke being carried out in developed countries may not be relevant to the life of such a person living with stroke in Malawi, a developing country. The aim of this study was therefore to explore the perceived barriers to reintegration into the community experienced by stroke clients after discharge from MAP Kachere rehabilitation centre in Malawi. Information gained in the study will assist service providers working in low-resourced developing countries, to develop and implement interventions that are appropriate.

\section{METHODOLOGY Setting}

The study was conducted in Malawi at MAP Kachere Rehabilitation Centre and surrounding communities. This centre provides combined services of physiotherapy, occupational therapy and nursing. It also offers basic speech therapy to clients with speech problems. Clients spend an average of two months at the centre before being discharged back to their communities. Currently there is no follow-up rehabilitation service to the discharged clients.

\section{Research design}

An exploratory,qualitative research design was used to explore the lived experiences of stroke clients regarding barriers to their reintegration into the community after discharge in Malawi. A qualitative research paradigm is relevant in health service research. Pope and Mays (1995) observe that qualitative research not only allows health service researchers to access areas not amenable to quantitative research, but is also a vehicle for good quantitative research particularly in areas with very little previous investigation, such as exploring the barriers to reintegration experienced by stroke patients in Malawi.

\section{Participants}

Convenience sampling was used to select stroke clients $(n=8)$ among the client population $(\mathrm{N}=22)$ who had been living for nearly one year in the community after discharge. The number of participants in the study was in line with recommendations by different authors in qualitative research. For instance Cresswell (1998) recommends 5 to 25 participants, and Kuzel (1992) suggests that 6 to 8 participants are enough for a homogeneous sample. The participants were selected from the centre's stroke registry among the clients who were discharged from the beginning of year 2010, could speak, and lived in surrounding communities.

\section{Data collection}

Individualised in-depth interviews were used to collect data from stroke clients, in their natural settings. The in-depth interviews started with one general open-ended question, followed by probing for detail, based on what the participant's response was (Britten 1995). The research aim, assurance of confidentiality, and declaration of the clients' freedom to withdraw at any point should they no longer want to continue, were articulated before any interview was conducted.

The study started after ethical clearance was obtained from University of the Western Cape's Senate Research Ethics Committee (South Africa), and the College of Medicine Research Ethics Committee (Malawi).Institutional approval to carry out the research at MAP Kachere Rehabilitation Centre was also secured. With the help of the head of department at the rehabilitation centre, the participants were identified with the use of registers and patient files. Individual calls were then made to the participants and their carers, and appointments for interviews were arranged. The interviews for the clients took place in their homes and lasted an average of 30 minutes. With participants' consent, data was captured by a voice recorder, and some was written down in the course of the interviews, all of which were conducted by the researcher.

\section{Data analysis}

Recorded interviews were transcribed verbatim by independent transcribers at the College of Medicine. Three of the eight interviews were sent for translation from Chichewa to English, and together, they were peer-reviewed by two physiotherapists working at Rehabilitation Technicians School. One interview transcript was declared null and void by agreement between the researcher, research assistant and peer reviewers, as lacking clarity because of the articulation problem of Participant P/IDI/5. Because of faulty articulation, the experiences of this interviewee might not have been fully captured, and would thereby affect the representativeness of his experiences (Jacobsnd). This reduced the number of interviews to $(n=7)$. Qualitative content analysis was employed based on the framework of qualitative concepts by Graneheim and Lundman (2004). According to this framework, data was grouped into meaning units, which were later reduced to units of analysis and then content areas, from which categories, codes and finally themes were developed. The thesis supervisor acted as peer reviewer during this process.

\section{Trustworthiness}

To ensure credibility and confirmability of the transcribed data, it was peer reviewed by colleagues and the thesis supervisor. The transcriptions were also presented to participants for verification. To further ensure trustworthiness the researcher provided a clear description of the research methods.

\section{Ethical considerations}

Ethical clearance for this study was granted by the Senate, Research Grants and Study Leave Committee at UWC, and the College of Medicine Research Ethics Committee. All measures were taken to protect the feelings, rights, and privacy of the participants. For instance,pseudonyms were used instead of names on all data sheets, and each participant consented to participation in this study.

\section{RESULTS}

The mean age of the participants was 54 years with a standard deviation of 5.2 years. The majority $(6 / 7)$ of the participants were married and lived with their spouses. One woman was widowed and lived with her sister. Four participants reported being employed before the stroke, but none had returned to work at the time of the interview. 


\section{BARRIERS TO REINTEGRATION AT ENVIRONMENTAL LEVEL}

Three sub-themes emerged as constituting environmental barriers. These were: attitudinal barriers, limitation by environmental physical factors, and resource limitation.

\section{Attitudinal barriers}

Under the sub-theme attitudinal barriers, four categories existed, one being change in attitude by friends, relatives, and other community members, and the other being change in attitude by employers/business associates/clients, business as usual attitude by public service providers and authorities and negative attitudes due to a lack of knowledge and awareness about stroke.

Change in attitude by friends, relatives, and other community members

Stroke clients in this study expressed their perception that people in the community were no longer the same; their attitude towards them had changed to varying extents. Most of them said they felt "obsolete" in the eyes of people in the community. For example, people in the community no longer maintained interest in visiting them, as described by one client,:" the people are the ones am talking about that maybe when I stand outside they greet me how are you? I answer then they go on."(P/IDI/1)This is so because stroke clients are no longer productive, so that when those people do come to visit they do not get any economic benefit as they did before the stroke. This is evidenced in: "I think I have friends but not many. I have them but they used to come when I am okay, because even my relatives they don't show up so often... as compared to the time I was okay, because I used to have money. They can't waste time with me ... because if they come, what will they get?" (P/IDI/2)

\section{Change in attitude by employers and business clientele}

Change in attitude of employers and/ or business clientele led to stroke clients having problems in returning to their former jobs (for those who were employed prior to stroke) or some jobs that stroke clients were engaged in for survival prior to stroke. Failure to go to their former jobs was due to the negative attitudes of employers or because business clientele made life in the community after stroke difficult for the clients and their families.

Stroke clients emphasised that they had problems carrying out work with former clients as consumers no longer trusted that after stroke the clients could do a good job for them. For example a client who was a consultant prior to stroke said that he had a problem securing an order after stroke: "I get paid though I mainly talking I answer their question -mmhahm-.. -ahm- I can answer their questions but normally what happens is that the people that I - I hear are not comfortable to bring their work to me because of the way they -erlooking at me." (P/IDI/2)

\section{Business as usual attitude by public service providers and authorities}

The attitudes of some public health providers create problems for stroke clients in accessing health or medical services in the community. For example, they point out that because organisationally there is no special arrangement for people with physical challenges, such as weakness from stroke, they find it difficult to compete with able-bodied people when they want to access services. One participant said: "Ii- at Queens it is difficult to go - mh- you go but you need to leave very early $-\mathrm{mh}-$ and reach there before they open $-\mathrm{mh}-$ and be on the queue $-\mathrm{mh}$ - that means you will be able to get the medication."(P/IDI/8)

\section{Negative attitudes due to lack of knowledge and awareness about stroke}

The study shows that there are specific negative behaviours of people owing to a lack of knowledge about stroke and its complications. These behaviours also affect stroke clients' ability to reintegrate into the community.

Participants in this study said people in the family and community did not seem to be well informed about stroke conditions. One client spoke about how his family was not providing satisfactorily what he needed; it seemed he knew what he wanted but people around him did not: "-ahg- I can say that am getting the attention, but -ah- the attention am getting as compare to the time I was okay, $-\mathrm{mm}-.$. , is a bit different ... yes because the attention that I-ha- I get is when I am demanding something -ah mmm-... but normally -ahm- I don't get anything more than that." (Talks to the son) $(\mathrm{P} / \mathrm{IDI} / 2)$
Some clients said people in the community did not seem to know what stroke is all about. This made them not appreciate the difficulties a person with stroke might be experiencing: "But it's bad to be difficult to integrate back into the community because it is you who feels something needs to be done not that, that other people." (P/IDI/4)

In many instances, a lack of awareness was shown by people's reactions when they saw somebody with stroke walking: "The people we meet in the streets stop to look at us wondering since they don't know it happened somewhere here I just came, others don't know what happened others know that am sick but they don't know what am suffering from -eeh yes. Iiiiii- I get worried.-hmmm.Eeeh I really get worried.” (P/IDI/7)

This demoralises stroke clients and leads to their opting to remain indoors and fail to participate in community activities, as shown in the following:" $-\mathrm{Mh}$ - walking is the problem - $\mathrm{mh}$ - because before I could walk up to down there - mh eh- so when I was walking I could see people standing along the way looking as if a beast is coming or something $-\mathrm{mh}-$ so then I could see the way they were looking at me. So I came round once this way -mh- then - mh- I stopped I did not go again $-\mathrm{mh}-$. .'(P/IDI/8)

\section{Physical environmental factors as a barriers}

There were mainly three physical environmental factors that emerged, namely uneven terrain, long distance to places of interest, and inaccessible structures.

\section{Uneven terrain}

Stroke clients said the nature of the road is a big concern when it comes to moving from place to place, owing to poor terrain. One client said: "You can see-ah- the road that you have walk to come to here. That means -mmm- somebody like myself cannot walk properly in this road of this nature - er- (silences son) - mmmh- what can I say -aah- ...”(P/IDI/2)

\section{Long distance to places of interest}

Sometimes because of a long distance to places, stroke clients may fail to reach such places because of difficulties with travelling. Some clients said that many places of interest were far from where they live: "For me to travel on public transport to board minibus - eeh- when I board off the taxi there is a long distance 
to the centre (trading centre) - eh- it is far because now it seems am walking like this so -ehh- to walk it becomes difficult. -Mmh-" (P/IDI/7)

\section{Inaccessible structures}

Stroke clients said some buildings with steps are not accessible to somebody who has mobility problems:, “-Aaahthis is all its difficult when it comes to steps, that is very difficult, -yaahMmh-, I really have to judge exactly how you are going to do it -yaah-." (P/IDI/4)

\section{Resource limitation}

Resource limitation as a barrier in the current study has emerged at three levels: household, community, and organisational.

\section{Resource limitation at household level}

Limitation of financial resources due to poverty, employer policy, and cost of disability related to transport, has been highlighted. Stroke clients in this study highlighted the difficulties they experienced in accessing public medical services as being due to poverty, and that it needed more money for transport, which they often did not have: "If we say no to Queens, because at Queens it's free whereas Mlambe, the hospital which is close is Mlambe but requires money so if you do not have money you cannot go... it is difficult we just try to get a minibus here to get treatment at Queens.'(P/ IDI/1)

Lack of financial resources at household level was exacerbated by some employment policies. For example, one client said he was not maintained on the payroll because stroke made him go beyond the recommended sick leave, which according to his employer,was three months: "It's because am not been paid I think they stopped 3 months ago. Yaah, not losing work but I think they have a condition to say you cannot be sick for more than 3 months and continue being paid." (P/IDI/4)

\section{Resource limitation at community level}

Lack of mobility aids, portable water and access to information were highlighted by stroke clients. They pointed out that public resources accessible to somebody living with stroke in the community are limited. One client particularly said there is a lack of mobility aids and portable water that is accessible to a woman living with stroke impairment: "Government should be giving those with stroke things to aid them in walking, like giving them the right support to help them in their life it would be better that just staying. -Eeeh- like there are wheelchairs, sticks, another thing for example a bore hole nearby."(P/IDI/1) Another client said there were no extra services such as home visits by social workers:"If I want to get medical attention, I have to go out. There is nobody -ah- from any hospital who comes here. Yes." (P/IDI/2)

Another thing that was difficult to get in the community was information or news about what was happening in the community. This was so because of inability of stroke clients to go out and interact, as one participant explained: "these days you will just hear that there was a funeral there - eh- without spreading the word in the lines may be things changed $-\mathrm{ah}-\ldots$ but for someone to come from there to visit, no." (P/IDI/8)

\section{Resource limitation at organisational level}

In this section, limitation of finances, staff, and training equipment were highlighted as affecting the smooth running of rehabilitation services at organisational level. Participants felt that there were shortages of staff and a shortage of equipment at MAP Kachere Rehabilitation Centre, and a general concern was that services were not reaching other disadvantaged people, as observed by this client: "It has just been difficult that -ah- there not enough rehabilitation workers but we people are coming from different areas like I come from inside Blantyre yet other people come from far" (P/IDI/7)

\section{DISCUSSION}

The aim of the study was explore the barriers to reintegration into the community experienced by stroke clients after discharge from a rehabilitation centre in Malawi. Two main themes emerged as barriers to reintegration into the community. The present study only reports on the environmental barriers experienced by the participants.

Environmental barriers that were discussed included attitudinal barriers, physical environmental barriers and resource limitation. The study showed that stroke clients' reintegration was affected by the changes in attitude of friends, relatives and other members of the community, as well as changes in the attitude of employers. The participants observed that they felt obsolete in the eyes of people in the community. They said that people did not visit them because, unlike the time before their stroke, they were not productive now, so that when people visited them the visitors did not get any benefit from it. This development, therefore, led to a reduction in contacts and interactions with other community members. The attitudes held by people towards a disabled member and their families led to difficulties with participation in the communities by disabled persons generally (Yeo and Moor 2003). Stroke clients in this study understood that some negative attitudes or behaviours by some members of the community were due to a lack of knowledge about stroke. Some community members, for example, would become inquisitive when they saw a stroke client walk, as evidenced in this quote by a participant:"The people we meet in the streets stop to look at us wondering ... I really get worried." (P/IDI/7) This contributed to the inability of stroke clients to remain mobile and participate in community activities. Lack of understanding was seen as a factor that limits a better life for disabled people in the community as it reinforces negative attitudes by members of the public towards disability (WHO and the World Bank 2011).

In addition to having experienced a change in the attitudes of family and the community, the participants also experienced changes in the attitudes towards them as business owners and employers. For example, stroke clients said they were no longer approached for contracts or deals by members of the public (business associates/clients), and perceived that the clientele was questioning the abilities of the person after stroke. This mostly affected those clients who were consultants before stroke. In addition, this shows that employers may stereotype stroke clients in that they do not consider them able to recover and come back to their work. They therefore end up relieving them of their duties.

Studies on attitudes of employers towards stroke clients have produced mixed outcomes. Those clients who find that work colleagues or managers are not supportive and do not recognise and help them, find returning to work difficult (Alaszewskiet al 2007). Perceived nega- 
tive stances by employers could emanate from underlying organisational policies (Yeo and Moor 2003). The present study shows that some stroke clients are not maintained on the pay role after a certain period of sick leave, as the policy of an organisation. Participants said that such policies are not supportive to the employee who suffers a stroke, and it affects them economically. This finding is in line with the observation that disabled people are marginalised by laws, policies, customs and/or practices; for example, some employers do not consider the requirements of disabled employees (Yeo and Moor 2003).

In the present study, three forms of barriers relating to the physical environment emerged, namely uneven terrain, long distance to places of interest, and inaccessible structures. Stroke clients explained that they faced difficulties moving from place to place because of land formation which is either steep or full of potholes. In the areas where the study was carried out, it is observable that the land was generally not flat, roads to some local communities were not tarred, and some places were full of sand which could be difficult to walk on or propel a wheelchair on. Mobility in the community should enable citizens to access community destinations to pursue daily activities. However, the negative effect of poor terrain on mobility is well known (Barker et al 2006). The finding in the current study concurs with results of the qualitative study by Barker et al (2006), in which "uneven sidewalks, rough ground such as potholes and grass", were perceived as limiting the mobility of stroke clients in wheelchairs.

Participants made similar observations that clients could not access some places and services such as taxi stages and public hospitals because they were too far from where they lived. Therefore, it became difficult to access basic services such as medical assistance. This result concurs with findings from a study in New Guinea by Shaw (2004) in which the author reported that rehabilitation and medical services were often located at places far from where persons with disabilities live. The distance, therefore, makes it difficult for them to access the services. In Malawi, poor networks of health services have also been reported, particularly in rural areas where, because of distance, people face difficulties accessing services, including medical assistance (Hofman et al 2008). The findings of the present study also concur with the results of research by Mony (2002) who reports that access to water sources in communities can be difficult because of long distances and lack of alternatives in nearby areas among disabled people. Inability to access places and services outside the stroke clients' homes may lead to them feeling cut off from the outside world and of no importance to it. Clients are also likely to experience poor health from a lack of timely access to health services (Shaw 2004).

Again,participants in the present study had similar observations that some stroke clients were not able to access buildings that had steps. The findings in this study concur with results of a qualitative study by Barker et al (2006) who reported that stroke clients have difficulty with "heavy doors, narrow store aisles, stairs,...inaccessible washrooms, and difficulties getting the wheelchair into the car." Disability issues in Malawi are a relatively new area of interest to policy makers, therefore public structures and buildings are mostly not disability-friendly (MSDPD Malawi 2006). This may validate the perceptions of the participants in the current study about inaccessibility to structures.

In addition to the above barriers the participants also expressed limitations in availability of resources. The participants perceived that stroke clients experience poverty at household level. They said a lack of money made it difficult to travel by taxi from place to place, in pursuit of medical and other services. This observation may not be unique to the average population, because according to the Integrated Household Survey $2004 / 05,52.4 \%$ of the population in Malawi lives below the poverty line, with the poorest people in the Southern Region (where this study took place) and rural areas being poorer than urban areas where poverty rates are at 25\% (Malawi Growth and Development Strategy 2006 - 2011). Poverty at household level therefore leads to difficulty in accessing the services, care and rehabilitation needed (May-Teerink 1999) and failure to participate in community activities.

In this study, the participants also talked about limitation of resources at community level. They said there was limitation in the provision of public resources in the community, such as mobility aids and portable water accessible by people with mobility problems such as stroke. Participants also said there was a lack of home-based care service, to support persons living with stroke disability. To the knowledge of the researcher, studies about community resources accessible to stroke clients in developing countries are rare. However, the problem with access to portable water concurs with a report by Gutierrez (2007) who says that due to the lack of access roads, poorer areas with less infrastructure in Malawi tend to get less water points. Sparse water points affect not only able-bodied people, but even more so affect people with mobility problems such as the female stroke clients who described this problem in the present study.

Lack of mobility aids may limit stroke clients' abilities to go out and participate in outdoor activities in the community, and a long distance to water points may affect the role of mainly female stroke clients who traditionally are expected to fetch water for their family. An inability to fulfil their role in this instance may lead to altered self-image by the clients, who may feel useless in not fulfilling their roles which are a domain in community reintegration (Obembe et al 2002).

\section{CONCLUSION}

The barriers experienced by the participants in the communities were wideranging. They included barriers such as attitudinal barriers, physical environmental barriers and resource limitation due to poverty at household and community levels.

This study highlights the need for service providers to adopt a holistic patient-centred approach (biopsychosocial model) when managing stroke clients, and a shift from the purely medical model. Further research and development into an appropriate model of care in resource-poor areas is recommended. 


\section{REFERENCES}

Alaszewski A, Alaszweski H, Potter J and Penhale B (2007) Working after a stroke: Survivors experiences and perceptions to and facilitators of the return to paid employment. Disability and Rehabilitation. 29(24): 1858-1869.

Barker DJ, Reid D and Cott C (2006)The experiences of senior stroke survivors: Factors in community participation among wheelchair users. Revue Canadienne D'ergotherapie, 1973: 18-25

Blondera LX, Langerd SL, Pettigrewb LC and Garritya TF. (2007) The effects of stroke disability on spousal caregivers. HYPERLINK "http:// iospress.metapress.com/content $/ 103177 / ? \mathrm{p}=548 \mathrm{fba} 7$ 0cd294ca4b4e2cd0c9c380265\&pi=0" Neurological Rehabilitation 22(2): 85-92

Britten, N. (1995) Qualitative Research: Qualitative interviews in Medical Research. British Medical Journal 311: 251-253.

Chau JPC, Thompson DR, Twinn S, Chang AM and Woo J. (2009) Determinants of participation restriction among community dwelling stroke survivors: a pathway analysis. BioMed Central Neurology 9 (49):1471 - 1477.

Cott CA, Wills R and Devitt R (2007). Continuity, transition and participation: Preparing clients for life in the community post-stroke. Disability and Rehabilitation 29 (20/21) 1566 -1574.

Creswell JW (2003). Research design: qualitative, quantitative and mixed method approaches. California: Sage Publication Inc.

Garcia LJ, Barrette J and Laroche C. (2000) Perceptions of the obstacles to work reintegration for persons with aphasia. Aphasiology 14(3), 269 - 290.

Graneheim UHand Lundman B (2004). Qualitative content analysis in nursing research: concepts, procedures, and measures to achieve trustworthiness. Nurse Education Today 24:105 - 112.
Gutierezz E (2007) Delivering pro-poor water and sanitation services: The technical and political challenges in Malawi and Zambia. Geoforum 38:886-900

Heeley EL, Wei JW, Carter K, Islam S, Thrift AG, Hankey GJ, Cass A and Anderson CS (2011). Socioeconomic disparities in stroke rates and outcome: pooled analysis of stroke incidence studies in Australia and New Zealand. Medical Journal of Australia, 195 (1): 10-14.

Hofman JJ, Dzimadzi C, Lungu K, Ratsma EY and Hussein J (2008) Motorcycle ambulances for the referral of obstetric emergencies in rural Malawi: Do they reduce delay and what do they cost? International Journal of Gynaecology and Obstetrics 102:191-197

Kochi L, Egbert N, Coeling H and Ayers D (2005) Returning to work after the onset of illness: Experiences of right hemisphere stroke survivors. Rehabilitation Counseling Bulletin, 48(4), 209-218.

Kuzel A. (1992). Sampling in qualitative inquiry. In Doing Qualitative Research, ed. B. Crabtree and W. Miller, 31-44. Newbury Park, California: Sage.

Loeb ME and Eide AH (2004) Living Conditions among People with Activity Limitations in Malawi. A National Representative Study. SINTEF Health Research 1 - 179.

Mayo NE, Wood-Dauphinee S, Cote R, Durcam L and Carlton J (2002) Activity, participation and quality of life 6 months post stroke. Archives of Physical Medicine Rehabilitation, 83:1035 - 1042.

Mays N and Pope C (2000) 'Qualitative research in health care: Assessing quality in qualitative research." British Medical Journal 320:50-52

May-Teerink T(1999) A survey of rehabilitative services and people coping with physical disabilities in Uganda, East Africa. International Journal of Rehabilitation Research 22(4):311-316

Mony, P. (2002) Disability Action Council. Cambodia.
Obembe AO, Johnson OE and Fasuy T.F (2002) Community reintegration among stroke survivors in Osun, South West Nigeria. African Journal of Neurological Sciences, 29(1).

Ottenbacher KJ, and Graham JE (2007)The state-ofthe-science: access to post-acute care rehabilitation services: A review. Archives of Physical Medicine and Rehabilitation, 88:1513 1521.

ShawA (2004) Rehabilitation services in Papua New Ginea. Papua and New Guinea MedicalJournal 47:215-227.

The Dakar framework for action: Education for All: meeting our collective commitments (2000, April 26-28). Adopted by the World Education Forum, Dakar, United Nations Educational, Scientific and Cultural Organization, Paris.

Venter C, Savill T, Rickert T, Bogopane H, Venkatesh A, Camba, J,Mulikia N, Khaula C, Stone J and Maunder D (2002)Enhanced Accessibility for People with Disabilities Living In Urban Areas.Unpublished Project Report PR/INT/248/02. Department for International Development (UK) Engineering Knowledge and Research: Project R8016.

WHO Geneva. (2005). The World Health Organization warns of the rising threat of heart disease and stroke as overweight and obesity rapidly increase. Retrieved March 29, 2010, from: http:// www.who.int/mediacentre/news/releases/2005/pr44/ en/index.html.

WHO (2001). International Classification of Functioning, Disability and Health (ICF). Retrieved February 25, 2010, from: http://www.who.int/ classifications/icf/en/.

WHO and World Bank World Report on Disability 2011.

Yeo R and Moore K (2003) Including Disabled People in Poverty Reduction Work: "Nothing about Us, Without Us".World Development 31(3):571 - 590. 